\title{
Analysis on the Development Potential of Forest Tourism in China's National Forest Park-Case study of Heilongjiang Province
}

\author{
Yin Yue ${ }^{1, a}$, Jia Li ${ }^{2, b}$ \\ ${ }^{1}$ Agricultural and Forestry Economic Management Post Doctoral Station, Northeast Agricultural \\ University, Harbin 150000, China \\ School of Management, Heilongjiang University of Science and Technology, Harbin 150000, China \\ ${ }^{2}$ Agricultural and Forestry Economic Management Post Doctoral Station, Northeast Agricultural \\ University, Harbin 150000, China \\ a9166547@qq.com, b364695830@qq.com
}

Keywords: National Forest Park, forest tourism, tourism development potential

Abstract. In recent years, with the development of economy and the deterioration of the environment, the protection of the ecological environment and the conservation of resources have become the focus of attention of the state and the world. The development of Forest Park has become a task in the new era. The development of Forest Park and forest tourism in China has a unique nature. This paper analyzes the overall situation of the National Forest Park, and takes Heilongjiang Province as an example to analyze the potential of forest tourism development.

\section{Introduction}

China has a vast, vast territory and abundant resources, especially food is rich in forest resources. Northeast China and Inner Mongolia are important timber supply bases in China, and also an irreplaceable ecological barrier of Northeast Plain, Songliao plain and North China plain. However, at the end of the 1980s, with the rapid development of the national economy, the economic crisis and resource crisis appeared in the forestry development. Environmental degradation not only threatened the economic development, but also threatened human life. Governments around the world began to pay attention to environmental protection, and China paid more attention to the new trend of forestry development, and put forward the establishment of Forest Park with economic development value[1-8]. At the end of 90s twentieth Century, the State Forestry administration put forward "all forestry work must be closely around the center and improve the economic benefit", "city greening and mountainous area, desert area development governance" as the focus, improve the overall productivity of forestry and forestry workers and farmers to improve the living standards of the masses, open the Forest Park development situation[9-13].

In recent years, with the development of economy and the deterioration of the environment, the protection of the ecological environment and the conservation of resources have become the focus of attention of the state and the world[14-20]. The development of Forest Park has become a task in the new era. In 2012, China pointed out at the eighteenth National Congress of the Communist Party report on the "comprehensive well-off society and deepening reform and opening up the goal", "to accelerate the establishment of ecological civilization system, improve the system and mechanism of land and space development, resource conservation, protection of the ecological environment, promote the formation of a new pattern of human and nature harmonious development of modernization." The eighth part of the report "vigorously promote the construction of ecological civilization", specifically on the ecological civilization construction issues, made plans for the future direction of the party and state work. "The optimization pattern of land development space, comprehensively promote resource conservation, increase natural ecosystems and environmental protection" and "strengthening the construction of ecological civilization system of four parts, the specific analysis includes eight theoretical innovation[21-28]:

(1) the establishment of the national park system; (2) the establishment of the carrying capacity of resources and environment monitoring and early warning mechanisms, the implementation of 
restrictive measures on Soil and water resources, environmental capacity and marine resources overload region; (3) to restrict the development of regional and ecological fragile national key counties for poverty alleviation and development, canceled GDP assessment; (4) exploration preparing the balance sheet of natural resources, the leading cadres to implement natural resource assets audit; (5) establish effective regulation of industrial land and residential land reasonable price mechanism, improve industrial land prices; (6) the establishment of attracting investment in social capital market mechanism to protect the ecological environment, the implementation of environmental pollution (third party governance; 7) to establish and improve the environmental protection management system of strict supervision of all emissions, independent environmental supervision and law enforcement; (8) establish co-ordination of the students Regional linkage mechanism for state system protection, restoration and pollution control. Among them, the establishment of "National Park System" has become the primary task in the construction of the system.

\section{Development Status of National Forest Park}

The term "National Park" originated in the United States. In 1872, the United States established the world's first "Yellowstone National Park"". According to the World Conservation Union (IUCN) unified definition, "National Park is mainly used for natural land or marine conservation and recreational activities of the ecological system, designated for protecting the integrity of one or more ecosystems for present and future generations; eliminate any form of damage to the development and protection management the act of possessing; provide spiritual, science and education, entertainment and sightseeing base for the people, for the protection of protected areas and entertainment ecosystem." According to the characteristics of our country, "National Park" is defined as: "the protection and management of the government designated, with human resources and natural landscape resources, for the purpose of both scientific research and education, protection and recreation and community development work, is a specific area to achieve effective protection and reasonable utilization of resources". Chinese National Park System in the department management system gradually evolved into 7 types: National Nature Reserve, National Forest Park, National Geological Park, National Wetland Park, National Mine Park, national key scenic area and National Water Conservancy Scenic area." The term "National Forest Park" is mainly used in the mainland of China, and is the most advanced of all kinds of Forest Park. The Forest Park is divided into China national Forest Park, Forest Park and Forest Park provincial city and county level three, which refers to the national Forest Park forest landscape beautiful scenery of humanities is relatively concentrated, ornamental, scientific, cultural value, special geographical location, with regional some representation, tourism service facilities, have high visibility but, for people to visit, rest or scientific, cultural and educational activities, by the State Forestry Bureau made a decision to set up the administrative license granted.

China's first truly national park in Heilongjiang province is the National Park of China, and then opened the National Park Construction in China started; the first building of the national Forest Park was established in 1982 in Zhangjiajie national Forest Park. To establish a National Forest Park image, promoting the construction of national Forest Park of standardization, the State Forestry Administration issued a notice in February 28, 2006, decided to enable the "China national Forest Park logo", also issued a "China national Forest Park special signs using interim measures". As of the end of 2012, China had 765 national Forest Park and 1 national forest tourist area, the number of provinces in Figure 1-1; the average annual growth of 388652.3 hectares, Figure 1 shows the number of annual growth area, as of the end of 2012 reached a total area of 12051116.64 hectares. 


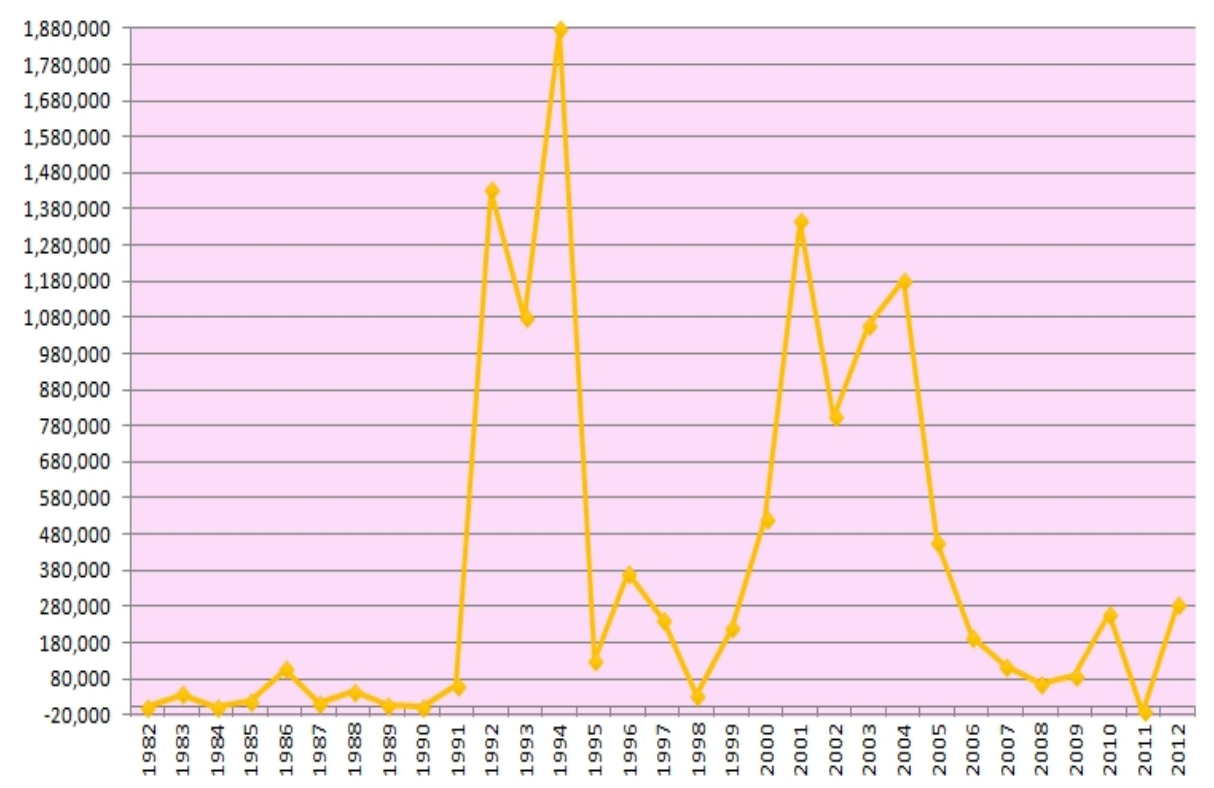

Fig. 1 New national Forest Park area

\section{Development Stages of Forest Tourism in China}

Since China's reform and opening to the outside world, forest tourism has developed vigorously. China's forest tourism has gone through three stages:

The first stage is from 1980 to 1990, the start of this stage is from China's first National Forest Park, Zhangjiajie National Forest Park building started, marking the beginning of the construction of National Forest Tourism in china. In the initial stage of the management characteristics of China's national Forest Park is the regional tourism less approval, the state investment in the park, the tourism industry has not formulated the perfect management, there is no legal construction and related institutions.

The second stage is from 1990 to 2000, Forest Park in China after ten years of construction and the management practice of forest tourism, social value, economic value, ecological value, has been recognized by all sectors of society. Local governments are increasingly enthusiastic about the development of forest tourism, which is a fast developing stage. The rapid development stage is characterized by a large quantity and fast growth, and Forest Park has sprung up all over china. The state's investment in Forest Park has been decreasing year by year, and the focus of investment has been on the development of local finance, loans and investment attraction. Complete types, from a single Forest Park developed into natural reserves, wildlife reserves, botanical gardens and other special forest tourism. At the stage of development, some standards or standards have been issued in our country, and the construction of forest tourism has been standardized and legalized.

The third stage is from 2000 till now, this stage is called the forest tourism system basic establishment stage, the main features of this stage is to improve the development of forest tourism thought, emphasizes the sustainable development, protect the ecological environment, adhere to humanism, change to the importance of physical planning, people ignore the bad habits care, is the embodiment of harmonious development, protect the natural ecological environment, adhere to the concept of sustainable development. In the management of forest tourism is also gradually improved.

\section{Development Potential of Tourism and National Forest Park Tourism}

According to the analysis of the second half of 2016 Chinese tourism economic situation report data, the number of domestic tourists will reach 2 billion 160 million passengers, the total revenue is expected to reach 1 trillion and 900 billion yuan rose $12.8 \%$, the tourism industry is the main battlefield of economic construction from economic construction to the edge of the steady growth, 
become the important industry structure, improve people's livelihood. In 2016, China's total tourism direct employment population was about 28 million 200 thousand, the total population of direct and indirect tourist employment was 79 million 740 thousand people, and the overall contribution rate of employment to the country was $10.25 \%$. Tourism led to consumption is very obvious, in the first half of this year; the country's domestic tourism consumption alone amounted to 1 trillion and 650 billion yuan, an increase of $14.5 \%$, higher than the total retail sales of consumer goods 4.1 percentage points higher. The tourism industry has become the largest industry comprehensive, its related industry for more than 110 of the lodging industry, the contribution rate of more than $90 \%$, civil aviation and rail passenger transport industry contribution rate of more than $80 \%$, the contribution of cultural entertainment industry rate of more than $50 \%$ of the catering industry and the contribution rate of more than $40 \%$ business. The transformation and upgrading of the tourism industry is the key to the future development of the "13th Five-Year" during the development of tourism industry will break through the traditional restrictions, and real estate, finance, pension, culture, agriculture, technology, education, creating a variety of new formats together to form a large comprehensive tourism industry system, give full play to the value-added effect tourism products. Tourism will take the initiative to integrate into the national strategy and give full play to the advantages of integrated industries. Is expected to "13th Five-Year" period, Chinese will be "The Belt and Road" countries along the transport 150 million visitors and $\$ 200$ billion in tourism consumption, and will attract 85 million tourists along the country, stimulating tourism consumption of about $\$ 110$ billion.

Forest tourism in China began to develop rapidly in 2000, established a forest tourism system, and the number of National Forest Park gradually increased, especially in recent years, the number of rapid rise. According to the 2014 data show that the forest tourism reception 709 million 800 thousand tourists to 1 billion 50 million passengers, to 2016, the number of tourists increased to 3 billion 110 million passengers; tourism total output value from 70 billion 977 million yuan in 2014, rose to 259 billion 854 million yuan in 2016; from the point of view of employment, the Forest Park social tourism staff of about 792 thousand and 600 people. The construction of the tourism industry and National Forest Park led to the development of forest area and the surrounding areas, urban transportation, culture and social services and other related industries have been developed, the irreplaceable role in stimulating the local economy. According to the statistics of China's East, West, northeast four regions found that China is now the Forest Park development is not balanced, the Northeast total number of small but the total area is relatively large, national Forest Park area, and below the provincial Forest Park number is relatively small; however, the number of Forest Park in the western region is not large, but the largest area.

Table 1 Statistics of the number and area of Forest Park in China

\begin{tabular}{llllll}
\hline \multicolumn{1}{c}{ Area } & Total Number & National quantity & $\begin{array}{c}\text { National area } \\
\left(\mathbf{h m}^{\mathbf{2}}\right)\end{array}$ & $\begin{array}{c}\text { Provincial } \\
\text { quantity }\end{array}$ & $\begin{array}{c}\text { Provincial area } \\
\left(\mathbf{h m}^{\mathbf{2}}\right)\end{array}$ \\
\hline East section & 1390 & 210 & 128.07 & 512 & 79.32 \\
Central section & 761 & 209 & 155.77 & 412 & 75.56 \\
West section & 719 & 252 & 541.97 & 394 & 199.81 \\
Northeast & 231 & 121 & 400.28 & 110 & 76.43 \\
section & & & & & \\
\hline
\end{tabular}

With the rapid development of China's economy and a high degree of material civilization, people are more and more yearning to return to nature. In recent years the city's industrialization and influence on the climate becomes more and more intense, extreme weather such as fog, dust storms continue to threaten people's health, fresh air, high content of negative oxygen ions, the pure spring has become a great "luxury", the forest has become the urgent need. With the increase of people's income level, there is a certain amount of funds for recreation and relaxation, according to the State 
Forestry Bureau statistics show that nearly 10 years of ecological tourism in China maintained a high growth rate of $30 \%, 30 \%-40 \%$ tourists turned to forest, according to the proportion of reckoning is expected to 2020, China's forest tourism industry output value will reach 300 billion yuan 2 million, the creation of employment opportunities. The development of forest tourism has been overwhelming.

\section{Forest Tourism Development Potential of Heilongjiang Province}

\section{Advantages of natural resources}

Heilongjiang has a total area of 20 million 70 thousand hectares of forest land, with a total area of 33 million 750 thousand hectares of forest management, with a forest coverage rate of $43.6 \%$. In the construction of Forest Park in 107, the national Forest Park in 63, the forestry system of wetland area of 1 million 540 thousand and 600 hectares, 139 nature reserves, nearly 500 kinds of wild animal, cold temperature with 2000 kinds of wild plants, there are a variety of edible fungi, the formation of the ecological resources of the rare. In addition, the province is rich in ice and snow resources, snow quality and long duration of snow, snow and ice brand is second to none, ice and snow culture unique charm. Building is located in the territory of Mudanjiang Shuangfeng forest farm "China snow village" is famous, the tourism sector has become the "light luxury goods; Yabuli ski resort is located in Shangzhi City is a result of the fifth, seventh and tenth Winter Games and the third Asian Winter Games and fame, the sub area become skiing endorsement. In addition, Heilongjiang province forest area cultural heritage, dinosaurs --- the hometown of Quaternary glacial relics of ancient human history; 170 thousand years ago, the Chai River lotus lake shore of the Han Dynasty Murals of ancient northern Mo Yan bright culture; Oroqen, Hezhe, Xibe, Manchu and other 10 ethnic minorities of the original ecological culture precious heritage. The minority culture, the Great Northern Wilderness culture, the red culture with the northern characteristics and the world-famous oil culture enhance the cultural background and resource advantages of Heilongjiang's forest tourism.

With the great support of the central government, forest tourism in Heilongjiang province has developed rapidly. Since 2000, Heilongjiang province has successfully created the forest ecological tourism zone, China Yabuli snow village, Lantau Peak, Pingshan, national Forest Park in 60, the National Geological Park 5 contains 1 World Geological Park has national wetland nature reserves 26, 52 National Wetland Parks in China; 49 world the wetland in Heilongjiang Province, there are 8; in the successful construction of Pingshan deer, riyuexia, Chinese Tieli snow village 10 ski tourism. As of 2016, Heilongjiang Province, the existing national Forest Park 63, Qinghe, Daqing, Suileng forestry bin Xianglushan declaration of Forest Park National Forest Park, has been through the national expert group review. In 2016, the province approved the "13th Five-Year" national natural and cultural heritage of national Forest Park three projects, access to the central investment of nearly 30 million yuan; actively follow up the central fiscal transfer payments ecological compensation funds, obtain 1 million 200 thousand yuan National Park forest transformation project funds. With the strong support of the state, Heilongjiang has developed a strong momentum in forest tourism.

\section{Leisure places for urban people}

With the rapid development of China's economy and the highly material civilization of the train, people are more eager to return to nature. In recent years the city's industrialization and influence on the climate becomes more and more intense, extreme weather such as fog, dust storms continue to threaten people's health, fresh air, high content of negative oxygen ions, the pure spring has become a great "luxury", the forest has become the urgent need. With the increase of people's income, there is a certain amount of money for recreation and relaxation. After 50 and 80, it has become the main force of forest tourism. Most have paid 50 after retirement, the idle rich, healthy, so become the main consumers of tourism industry, the majority of these people is the leader, but have not received high education, retirement after the start of the "learning", tourism is the rapid growth of knowledge and experience is 80 social channels; the mainstay has advanced ideas and higher cultural literacy, family have their own children, one is the work pressure need to relax, on the other hand is bearing the 
responsibility of educating children, so tourism is not only a sightseeing tour, there is a certain educational purpose. Forest Park scenic area and Heilongjiang province are mostly located in the outskirts of the city, people can use the weekend time to play, landform of Forest Park in Heilongjiang province varied, formed the mountain glaciers, lakes and waterfalls, springs, grassland type, type of Forest Park features, people can choose their own leisure experience, can also according to the seasonal variation of different types of forest tourism.

Needs of Heilongjiang province coal, oil city, forest city and other resource-based city supply side reform transformation

On May 201623 - 25, when general secretary Xi Jinping inspected Heilongjiang, he stressed again that the task of transferring the structure of Heilongjiang was arduous, and efforts should be made to optimize the industrial structure, to capacity, to inventory and to leverage. The coal industry overcapacity, the coal enterprises in Heilongjiang province is very careful; the coal city Hegang, Jixi, Shuangyashan, Qitaihe is facing a difficult transition. Also, the oil city of Daqing forestry city in Yichun are facing the special period of transition. To continue production and play the role of these resource-based cities, to bid farewell to the historical stage, and to develop the economy and tourism industry is the point. Daqing is known as "100 Lake City" title, has a large number of wetlands, build a national wetland park with congenital conditions; in addition to Daqing international theme park with much land and few people, like for the construction of large international parks such as "Disney Park". The construction of Tang Wanghe District in Yichun and the construction of Forest Park in the five camps have brought huge economic benefits to Yichun. According to the Tang Wanghe District of Yichun, in 2016, tourism revenue reached 60 million yuan in alone. It can be seen that the resource-based cities in Heilongjiang province have profound potential for tourism economic development.

In addition, the supply side structural reform of land policy has been made, such as the protection of a new form of new industrial land and revitalize the stock of inefficient construction land, promote the real estate and real estate inventory, to support social capital investment in railway land comprehensive development and rural land reform in three, the original once hot real estate driven by economic development the momentum is gone forever, real estate is gradually returning to normal, uniform development. The Heilongjiang Academy of Social Sciences, former Secretary of the Party committee: "to accelerate the upgrade to the fine and high quality of Heilongjiang Province, the life of service, we should vigorously develop modern finance, modern logistics, information services, culture and tourism industry, to create a new engine of economic growth, promote the development of the tourism industry is imperative.

\section{Conclusions}

The construction of China's National Forest Park as "13th Five-Year" key, and the forest tourism development along with the "The Belt and Road extension. The development of forest tourism is the economic development of our country and a growth point and driving force, its economic potential is limitless, the National Park forests in full swing on China's forest tourism can create a miracle of economic growth. Because of the forest tourism throughout the year, so according to different seasons can create different theme tourism projects, such as the spring "minority life experience", "forest small train" summer "forest oxygen bar", "teaching" and "scientific exploration", "survival", "forest Lodge experience", "autumn ornamental plant identification", "green agricultural products" picking "green delicacy tasting", "winter snow sports" and "spring snow" and "snow country train" igloo hotel experience ", which will contribute to personalized forest tourism projects for the economic development of our country. 


\section{Acknowledgments:}

The research of this article is supported by key research project of economic development of Heilongjiang Province in 2017 (No.: 2017119), and Heilongjiang postdoctoral research project "National Park strategy Super League research" No.LBH-Z14038.

\section{References}

[1] LAN Siren national Forest Park. The theory and practice of [M]. Beijing: Chinese Forestry Press, 2004:5-6.

[2] Xiao Duning. Principles and methods in landscape ecology [J]. geographic science, 1997,17 (4): $356-464$.

[3] Wu Wu. Study on Zhangjiajie national Forest Park [M]. Beijing: China Forestry Publishing House, 1991:3-4.

[4], Lan Siren, Dai Gang, Shen Sheng. Thirty years of Chinese Forest Park and forest tourism [J]. forestry economic issues, 2014,34 (2): 97-107.

[5] anonymous. Forest tourism industry has made significant progress in the exploration and development of new models [EB/OL]
(2014-8-14) [2015-4-13].http://caijing.iqilu.com/cjzx/2014/0814/2104098.shtml.

[6], Chen Xiaoqin, Liu Weiping, Chen Guisong. Statistical analysis of the core journals in China. Perspectives on the development of Forest Park studies [J]. forestry economic issues, 2012,32 (2): 143-148.

[7] Li Bifang. Comprehensive evaluation of forest landscape in Forest Park [J]. subtropical plant science, 2009,38 (2): 85-88.

[8], Li Shidong, Chen Xinfeng. China Forest Park and forest tourism research [J]. Journal of tourism development, 2007,22 (5): 66-72.

[9], Li Baiqing, Wu Chucai, Wu Zhangwen. Direction of development of Forest Park in China [J]. Chinese Journal of ecology, 2009,29 (5): 2749-2757.

[10], Qiu Xiaoxia. Review of tourism development and planning of Forest Park in China. [J]. resources development and markets, 2008,24 (1): 77-80.

[11] Wei, Nini, Li Hongbo, Wang Xingguo. Review of the research on Forest Park in the perspective of leisure tourism [J]. Journal of Guangxi Economic Management Cadre College, 2013,25 (3): 57-63.

[12], Wang Yan, Chen Xinfeng. Application of psychophysical methods to the evaluation of forest landscapes abroad. [J]. forestry science, 1999,35 (5): 110-117.

[13], Guo Jinping, Zhang Yunxiang. Progress and Prospect of forest landscape ecology research in China [J]. world forestry research, 2003, 16 (5): 46-49.

[14] Caigen Yang, Guo Jianying. Over the past ten years in China Forest Park tourism research [J]. Anhui Agricultural Sciences, 2009, 37 (3): 1278-1280.

[15] Yang Fan. Present situation and development trend of landscape design in Forest Park. [J]. Sino South Forestry survey program, 2000, 19 (1): 43-46.

[16] Zhang Yichuan, Qiao Lifang, Chen Liangming, Qi Anguo. Forest Park construction the present situation and Prospect of [J]. Fujian forestry science and technology, 2004, 31 (3): 91-94. 
[17] Zhang Jinhe,Lu Lin. Dissertation China tourism [J]. analysis of geography science, 2003, 23 (4): 504-511.

[18] Zhang Li. Looking at the discipline construction and research focus of Library Science in China from the master thesis. [J]. library work and research, 2009 (4): 80-84.

[19]National, Park, Service., General, Management, Planning, Dynamic, Sourcebook[R]., 2th, ed.,, U.S.: NPS,...

[20] Li Li. Legal foundation of American National Park. [J]. Chinese garden, 2002 (5):7-13.

[21] Yang Rui. Legislation and enforcement of national parks in the United States. [J]. Chinese garden, 2003 (5):63-66.

[22]Sheehan, LR, Ritchie, JR.Destination, Stakeholders:Exploring, Identity, And, Salience[J].Annals, of, Tourism, Research, 2005,22 (3): 711-734.

[23] Zhou Ling. Interest in tourism planning and management related research progress of [J]. Tourism Tribune, 2004 (06): 53-60.

[24] Huang Dayong, Du Yiran. Tourism development stakeholders review [J]. Natural Science Journal of Industrial and Commercial University Of Chongqing, 2015,32 (2): 71-76.

[25] Zhu Taoxing, Lu Lin. Nearly 10 years of cultural tourism research progress - "Tourism Management", "Annals of Tourism Research" and "Tourism Tribune" review of [J]. Tourism Tribune, 2005 (06): 82-89.

[26] Zhang Yi. Advances in the study of forest culture in China in recent years [J]. Chinese Agricultural Science Bulletin, 2009,25 (21): 122-126.

[27] Zhang Lingyun, Nao Li, Liu Min. The wisdom of tourism basic concept and theoretical system of [J]. Tourism Tribune, 2007 (05): 66-74.

[28]Liu Junlin, Fan Yunfeng. The composition, value and development trend of Intelligent Tourism [J]. Chongqing Social Sciences, 2011 (10): 121-124. 